\title{
MicroRNA-216b-3p inhibits lung adenocarcinoma cell growth via regulating PDZ binding kinase/T-LAK-cell-originated protein kinase
}

\author{
YAQIN CHAI $^{1 *}$, HUIJUN XUE $^{2 *}$, YANMEI WU ${ }^{1}$, XIAOMEI DU ${ }^{1}$, ZHUOHONG ZHANG $^{1}$, \\ YINLIANG ZHANG $^{1}$, LILI ZHANG $^{1}$, SHUANBAO ZHANG ${ }^{1}$, ZHIGUO ZHANG ${ }^{1}$ and ZHIWEN XUE ${ }^{1}$ \\ ${ }^{1}$ Department of Respiratory Medicine, Xi'an XD Group Hospital, Xi'an, Shaanxi 710077; \\ ${ }^{2}$ Department of Respiratory Medicine, Xijing Hospital, Xi'an, Shaanxi 710032, P.R. China
}

Received August 11, 2017; Accepted December 1, 2017

DOI: $10.3892 /$ etm.2018.6020

\begin{abstract}
Numerous studies have reported that microRNA (miR)-216b, as a tumor suppressor, is downregulated in a variety of cancer types. PDZ binding kinase (PBK)/T-LAK-cell-originated protein kinase (TOPK) is highly expressed in various types of human cancer, including lung cancer. The expression of miR-216b-3p and its potential roles in lung adenocarcinoma are still unclear and no research has been conducted into the association between miR-216b-3p and PBK/TOPK. Thus, the present study aimed to investigate the expression and role of miR-216b-3p in lung adenocarcinoma and to explore whether PBK/TOPK is involved in the underlying mechanisms of lung adenocarcinoma. The expression of miR-216b-3p in lung adenocarcinoma cell lines was detected. $\mathrm{PBK} / \mathrm{TOPK}$ protein expression levels were also determined within lung adenocarcinoma cell lines. To investigate the association between miR-216b-3p and PBK/TOPK, TargetScan analysis was performed; PBK was predicted to be a potential target gene of miR-216b-3p, and a dual luciferase reporter assay was applied to confirm this prediction. To investigate the role of miR-216b-3p in lung adenocarcinoma, a lung adenocarcinoma cell line (GLC-82) was transfected with miR-216b-3p mimic or its negative control. An MTT assay was applied to detect cell proliferation, and cell apoptosis was analyzed by flow cytometry. Western blot analysis was performed to determine the protein expression levels of associated proteins. The results of the present study suggested that miR-216b-3p was downregulated in lung adenocarcinoma cell lines and
\end{abstract}

Correspondence to: Dr Zhiwen Xue, Department of Respiratory Medicine, Xi'an XD Group Hospital, 97 Fengdeng Road, Xi'an, Shaanxi 710077, P.R. China

E-mail: xuezhiwen201708@163.com

${ }^{*}$ Contributed equally

Key words: PDZ binding kinase/T-LAK-cell-originated protein kinase, microRNA-216b-3p, lung adenocarcinoma, cell growth
PBK/TOPK was highly expressed in lung adenocarcinoma cells. miR-216b-3p directly targets PBK and negatively regulates its expression. miR-216b-3p overexpression may inhibit GLC-82 cell proliferation and induce cell apoptosis. In addition, miR-216b-3p overexpression may increase p53 and p21 expression, and prevent p38 MAPK activation. These effects on GLC-82 cells caused by miR-216b-3p overexpression may be eliminated by PBK/TOPK overexpression. In conclusion, miR-216b-3p was downregulated in lung adenocarcinoma and may function as a tumor suppressor by inhibiting cell growth via regulating $\mathrm{PBK} / \mathrm{TOPK}$ expression.

\section{Introduction}

Lung cancer is a multistep process involving alterations in the expression of oncogenes and tumor suppressor genes via numerous factors, including alcohol, smoking, pathogenic infections and genetic factors (1-3). Lung cancer is the most frequently diagnosed cancer and its incidence has been increasing in recent years $(2,3)$. It remains a leading cause of cancer-associated mortality worldwide for men and women $(4,5)$, but the pathogenesis of this disease remains unknown (6).

PDZ-binding-kinase/T-LAK cell-originated protein kinase (PBK/TOPK) is a 322-amino acid serine/threonine kinase (7). In normal tissues, is difficult to detect PBK/TOPK protein, other than in the germ cells of the testis and numerous fetal tissues (8). The overexpression of PBK/TOPK has been observed in activated T-LAK cells, which interacted with fruit plate-large human homologues via the C-terminal PDZ binding motif of TOPK (9). PBK/TOPK is widely expressed in a variety of malignancies, including leukemia, lymphoma and breast cancer, and malignant peripheral nerve sheath tumors (10-12). $\mathrm{PBK} / \mathrm{TOPK}$ overexpression contributes to tumor proliferation and growth in Ewing sarcoma, colorectal cancer and breast cancer $(13,14)$. In lung cancer, patients exhibit poor clinical outcome with high expression of PBK/TOPK (15). Recently, PBK/TOPK overexpression was reported to be closely associated with tumor malignancy potential and poor outcome of patients with gastric cancer (16). In addition, high expression of PBK/TOPK may serve as a favorable prognostic marker for 
patients with oral cancer (17). In molecular studies, PBK/TOPK expression was associated with cell mitotic regulation, inflammation and apoptosis (18).

MicroRNAs (miRNAs/miRs) are non-coding RNAs that inhibit gene expression by inhibiting the translation of target mRNAs or by degrading them. miRNAs have been demonstrated to interact directly with the 3'-untranslated region (3'-UTR) of target mRNAs (19). miRNAs regulate numerous cell functions, including proliferation, differentiation, metastasis and apoptosis (19). Studies have indicated that altered miRNA expression levels are associated with cancer $(20,21)$. miRNAs may serve as oncogenes or tumor suppressors, depending on the organs and tumors in which they are expressed (22-24). miR-216b has been studied in a variety of cancer types. For instance, miR-216b was reported to be closely associated with the prognosis of cervical cancer patients and may inhibit cervical cancer cell proliferation via regulating forkhead box protein M1 (FOXM1) expression (25). miR-216b prevented the migration and invasion of glioma cells by suppressing FOXM1 expression (26). Liu et al (27) reported that miR-216b was involved in cisplatin resistance in ovarian cancer by the regulation of poly adenosine 5'-diphosphate-ribose polymerase 1. Furthermore, miR-216b may inhibit hepatocellular carcinoma cell proliferation, migration and invasion by regulating insulin-like growth factor 2 mRNA-binding protein 2 (28). However, the role and mechanism of miR-216b-3p in lung adenocarcinoma requires further investigation.

The present study aimed to explore the effects of miR-216b-3p on lung adenocarcinoma, and the association between miR-216b-3p and PBK/TOPK. Herein, the molecular functions and underlying mechanism of miR-216b-3p were investigated.

\section{Materials and methods}

Reagents. Human lung adenocarcinoma cell lines (A549, GLC-82 and H358 cells) and the human normal lung epithelial cell line BEAS-2B were acquired from Scien Cell Research Laboratories, Inc. (San Diego, CA, USA) and cultured in the laboratory. Fetal bovine serum (FBS), penicillin/streptomycin, and trypsin-EDTA were obtained from Gibco (Thermo Fisher Scientific, Inc., Waltham, MA, USA). Dulbecco's modified Eagle medium (DMEM) was obtained from Corning, Inc. (Corning, NY, USA).

Cell culture. A549, GLC-82, H358 and BEAS-2B cells were cultured in DMEM containing 10\% FBS, $100 \mathrm{U} / \mathrm{ml}$ penicillin and $100 \mathrm{U} / \mathrm{ml}$ streptomycin $(\mathrm{pH} 7.2)$ in a $5 \% \mathrm{CO}_{2}$ atmosphere at $37^{\circ} \mathrm{C}$.

Reverse transcription-quantitative polymerase chain reaction (RT-qPCR) analysis. Total RNA was isolated from A549, GLC-82, H358 and BEAS-2B cells using TRIzol reagent (Invitrogen; Thermo Fisher Scientific, Inc.) according to the manufacturer's protocol. The first strand cDNA synthesis was performed with $1 \mu \mathrm{g}$ RNA in the reaction mixture of $10 \mu \mathrm{l}$ with 50 pmol random hexamers and 50 units of M-MLV RTase. Conditions were as following: $16^{\circ} \mathrm{C}$ for $30 \mathrm{~min}, 42^{\circ} \mathrm{C}$ for $30 \mathrm{~min}, 85^{\circ} \mathrm{C}$ for $5 \mathrm{~min}$, and hold at $4^{\circ} \mathrm{C}$. Subsequently,
qPCR was performed to analyze the synthesized cDNA using the QuantiTect SYBR Green PCR kit (Qiagen GmbH, Hilden, Germany). The master mix $(20 \mu \mathrm{l})$ contained $2 \mu \mathrm{l} 10 \mathrm{x}$ reverse transcription buffer, $1 \mu 1$ deoxynucleotides $(100 \mathrm{mM}$; with thymidine triphosphate), $0.25 \mu \mathrm{l} 2 \mu \mathrm{M}$ forward primer, $0.25 \mu \mathrm{l} 2 \mu \mathrm{M}$ reverse primer, $5 \mu \mathrm{l} 1 \mathrm{ng} / \mu \mathrm{l} \mathrm{cDNA}$ and $11.5 \mu \mathrm{l}$ nuclease-free water. The amplification conditions were as follows: 38 cycles of denaturation at $95^{\circ} \mathrm{C}$ for $10 \mathrm{sec}$, followed by $60^{\circ} \mathrm{C}$ for $60 \mathrm{sec}$ to allow annealing and extension. U6 and GAPDH served as the internal controls for miR-216b-3p and PBK expression respectively. qPCR was conducted with the following primers: miR-216b-3p forward, 5'-CAGGCACAC ACTTACCCGTA-3' and reverse, 5'-GCAGGGTCCGAG GTATTC-3'; U6 forward, 5'-CTCGCTTCGGCAGCACAT ATACT-3' and reverse, 5'-ACGCTTCACGAATTTGCGTGT C-3'; GAPDH forward, 5'-GAAGGTGAAGGTCGGAGT C-3' and reverse, 5'-GAAGATGGTGATGGGATTTC-3'; and PBK forward, 5'-CCAAACATTGTTGGTTATCGTGC-3' and reverse, 5'-GGCTGGCTTTATATCGTTCTTCT-3'. Relative gene expression was calculated by using the $2^{-\Delta \Delta \mathrm{Cq}}$ method (29). The test was performed three times in triplicate.

Western blot analysis. Harvested A549, GLC-82, H358 and BEAS-2B cells were briefly washed with cold PBS. On ice, they were lysed in radioimmunoprecipitation complete lysis buffer [50 mM Tris, $\mathrm{pH} 7.2 ; 1 \%$ sodium deoxycholate; $150 \mathrm{mM} \mathrm{NaCl} ; 0.1 \%$ SDS; $10 \mathrm{mM} \mathrm{NaF} ; 1 \%$ Triton-X 100; $1 \mathrm{mM}$ Na3VO4; protease inhibitor cocktail (1:800)]. Lysates were sonicated 3 times at $4^{\circ} \mathrm{C}$, each time $10 \mathrm{sec}$ (frequency, $20 \mathrm{kHz}$ ) and centrifuged at $13,000 \mathrm{x}$ g for $10 \mathrm{~min}$ at $4^{\circ} \mathrm{C}$. Serum albumin was used as the standard and protein concentration was determined with bicinchoninic acid as previously described (30). Total protein (30 $\mu \mathrm{g} / \mathrm{lane}) \mathrm{was}$ separated using $12 \%$ SDS-PAGE and transferred to polyvinylidene difluoride membranes. Subsequently, membranes were incubated with PBS containing $0.05 \%$ Tween-20 and $5 \%$ non-fat dry milk at room temperature for $1.5 \mathrm{~h}$ to block non-specific binding and were incubated with PBK/TOPK (cat no. 4942), p53 (Cat no. 2527), p21 (cat no. 2947), p-p38 (cat no. 4511) and $\beta$-actin (cat no. 4970) primary antibodies (all 1:1,000; Cell Signaling Technology, Danvers, MA, USA), then treated with anti-rabbit Immunoglobulin $\mathrm{G}$ horseradish peroxidase-coupled secondary antibody (cat no. 7074; 1:1,000; Cell Signaling Technology) as described (31). Immunoreactive bands were observed with enhanced chemiluminescence using the SignalFire ${ }^{\mathrm{TM}}$ Plus ECL Reagent (cat no. 12630; Cell Signaling Technology) and imaged by ChemiDoc XRS+ System (Bio-Rad Laboratories). The band density was quantified with Gel-Pro Analyzer densitometry software (version 6.3; Media Cybernetics, Inc., Rockville, MD, USA).

Transient transfection. Cells were transiently transfected with $50 \mathrm{nM}$ miR-216b-3p mimic (Pre-miR ${ }^{\mathrm{TM}}$ miR-216b-3p; sense, 5'-AAAUCUCUGCAGGCAAAUGUGA-3' and antisense, 5'-ACAUUUGCCUCCAGAGAUUUUU-3'; Thermo Fisher Scientific, Inc.), $50 \mathrm{nM}$ negative control (negative control miRNA; sense, 5'-UUCUCCGAACGUGUCACG UTT-3' and antisense, ACGUGACACGUUCGGAGAATT-3'; Thermo Fisher Scientific, Inc.), $2 \mu \mathrm{g}$ control plasmids, $2 \mu \mathrm{g}$ 
PBK/TOPK plasmids (PBK CRISPR/Cas9 KO Plasmid (h); cat no. sc-404069; Santa Cruz Biotechnology, Inc., Dallas, CA, USA) or $50 \mathrm{nM}$ miR-216b-3p mimic $+2 \mu \mathrm{g}$ PBK/TOPK plasmids using Lipofectamine ${ }^{\circledR} 2000$ (Invitrogen; Thermo Fisher Scientific, Inc.), according to the manufacturer's protocol. Cells were seeded at a density of $5 \times 10^{4}$ cells per well in a 6 -well plate. At $48 \mathrm{~h}$ post-transfection, the cells were subjected to subsequent analysis.

Luciferase reporter assay. Bioinformatics software (targetscan.org/vert_71) was used to predict the targets of miR-216b-3p; PBK was identified as a potential target of miR-216b-3p. To determine whether miR-216b-3p directly targets the 3'-UTR of PBK, the psiCHECK-2 reporter plasmid (Sangon Biotech Co., Ltd., Shanghai, China) vectors named PBK-3'UTR-WT and PBK-3'UTR-MUT with wild type and mutated 3'UTR of PBK mRNA, respectively, were constructed as previously described (32). GLC-82 cells $\left(5 \times 10^{4}\right.$ cells/well) were seeded in a $24-w e l l$ plate and then co-transfected with PBK-3'UTR-WT or PBK-3'UTR-MUT and miR-216b-3p or its negative control (miR-NC) vector using Lipofectamine ${ }^{\circledR} 2000$ transfection reagent according to the manufacturer's protocols. A total of $48 \mathrm{~h}$ after transfection, the luciferase activity was detected using the Dual-Luciferase Reporter Assay kit (Promega Corporation, Madison, WI, USA) according to the manufacturer's protocol and normalized to Renilla luciferase activity.

Flow cytometry for apoptosis analysis. For apoptosis analysis, $1 \times 10^{5}$ cells/well were seeded in 6-well plates and incubated in DMEM containing $10 \% \mathrm{FBS}$ at $37^{\circ} \mathrm{C}$ for $48 \mathrm{~h}$. After $48 \mathrm{~h}$, the harvested floating and adherent cells were washed twice with cold PBS. Cells were stained with Annexin V-fluorescein isothiocyanate and propidium iodide (cat. no. 6592; Cell Signaling Technology) in $500 \mu \mathrm{l}$ binding buffer at room temperature for $15 \mathrm{~min}$, and then analyzed with a BD FACSCelesta ${ }^{\mathrm{TM}}$ flow cytometer (BD Biosciences, Franklin Lakes, NJ, USA) using WinMDI (Version 2.5; Purdue University Cytometry Laboratories, West Lafayette, IN, USA) within 1 h (28).

Cell proliferation assay. Cell proliferation was examined by a MTT assay. A total of $48 \mathrm{~h}$ after transfection, GLC-82 cells $\left(4 \times 10^{3}\right.$ cells/well) were seeded into 96 -well culture plates and incubated in $5 \% \mathrm{CO}_{2}$ at $37^{\circ} \mathrm{C}$. Then, $20 \mu 1 \mathrm{MTT}(5 \mathrm{mg} / \mathrm{ml})$ was added to each well and the cells were incubated for another $4 \mathrm{~h}$ at $37^{\circ} \mathrm{C}$. Following removal of MTT, $100 \mu \mathrm{l}$ dimethyl sulfoxide was added to each well, and the plate was gently agitated for $10 \mathrm{~min}$ at room temperature. The absorbance was measured with a microplate reader (Bio-Rad Laboratories, Inc., Hercules, CA, USA) at $490 \mathrm{~nm}$. All experiments were repeated $\geq 3$ times (33).

Statistical analysis. Experiments were performed for at least three times. Data are expressed as the mean \pm standard deviation. SPSS 17.0 statistical software (SPSS, Inc., Chicago, IL, United States) was performed for all statistical analyses. Statistical analysis was performed using a Student's t-test or one-way analysis of variance followed by Tukey's test where appropriate. $\mathrm{P}<0.05$ was considered to indicate a statistically significant difference.

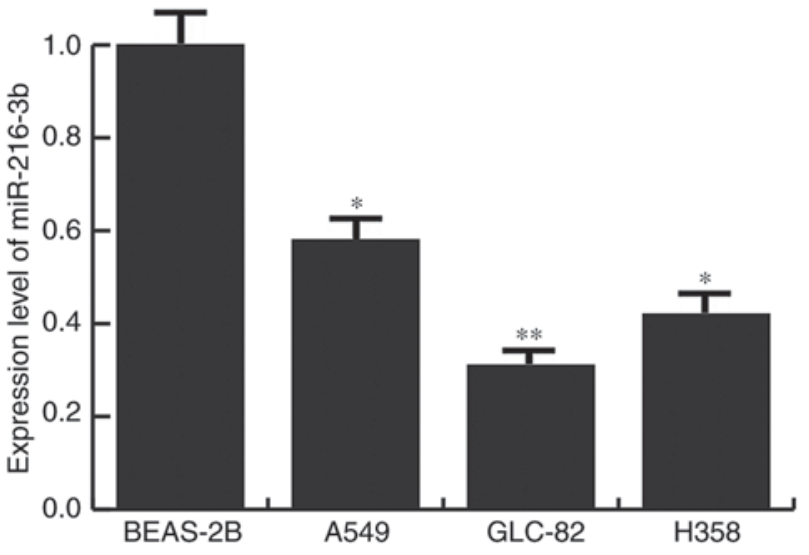

Figure 1. Expression levels of miR-216b-3p in lung adenocarcinoma cell lines. Relative miR-216b-3p expression levels in lung adenocarcinoma cell lines (A549, GLC-82 and H358) and human normal lung epithelial cell line, BEAS-2B, were determined by reverse transcription-quantitative polymerase chain reaction. Data are expressed as the mean \pm standard deviation. ${ }^{*} \mathrm{P}<0.05$ and ${ }^{* *} \mathrm{P}<0.01$ vs. BEAS-2B. miR, microRNA
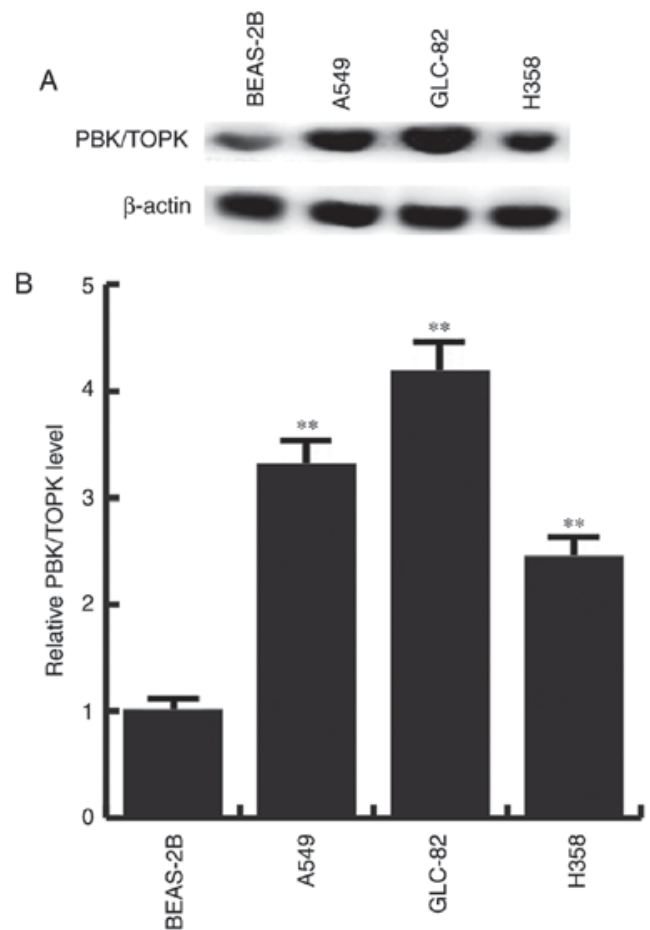

Figure 2. PBK/TOPK protein and mRNA expression levels in lung adenocarcinoma cell lines. (A) PBK/TOPK protein expression levels in lung adenocarcinoma cell lines (A549, GLC-82 and H358) and human normal lung epithelial cell line BEAS-2B; (B) PBK/TOPK mRNA expression levels in lung adenocarcinoma cell lines (A549, GLC-82 and H358) and human normal lung epithelial cell line BEAS-2B. Data are expressed as the mean \pm standard deviation. ${ }^{* *} \mathrm{P}<0.01$ vs. $B E A S-2 B . P B K / T O P K$, PDZ-binding-kinase/T-LAK cell-originated protein kinase.

\section{Results}

Low expression of miR-216b-3p in lung adenocarcinoma cell lines. The expression levels of miR-216b-3p in human lung adenocarcinoma cell lines (A549, GLC-82 and H358 cells) and human normal lung epithelial cell line BEAS-2B were analyzed. The results of the present study indicated that the 


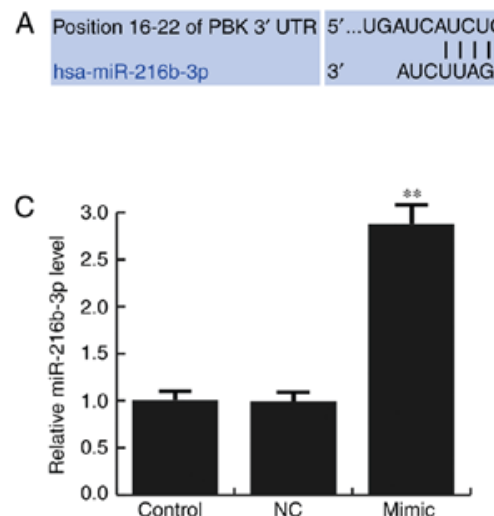

E

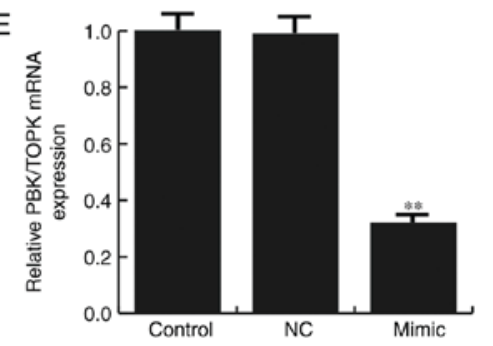

B

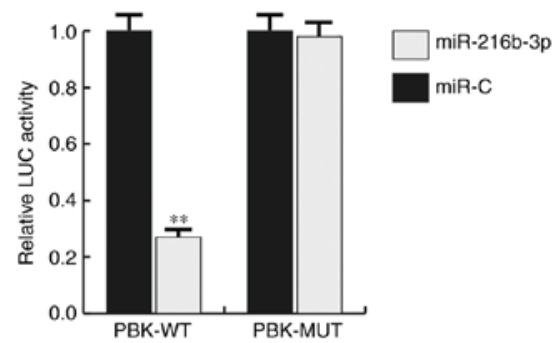

Figure 3. PBK is a target gene of miR-216b-3p. (A) TargetScan was applied to predict the interaction between miR-216b-3p and 3'UTR of PBK. (B) Luciferase activity was detected via a dual luciferase assay. (C) Relative miR-216b-3p expression levels in GLC-82 cells. (D) Effects of miR-216b-3p on PBK/TOPK protein expression in GLC-82 cells were determined by western blotting. (E) Effects of miR-216b-3p on PBK/TOPK mRNA expression in GLC-82 cells were determined by reverse transcription-quantitative polymerase chain reaction. (F) Relative PBK/TOPK mRNA expression levels in GLC-82 cells. Data are presented as the mean \pm standard deviation. ${ }^{* *} \mathrm{P}<0.01$ vs. control. Control, control group, cells without any treatment; NC, negative control group, cells transfected with the negative control vector of miR-216b-3p mimics; mimic, cells transfected with miR-216b-3p mimics; plasmid, cells transfected with PBK/TOPK plasmids; LUC, luciferase; miR, microRNA; PBK/TOPK, PDZ-binding-kinase/T-LAK cell-originated protein kinase; MUT, mutated 3'-untranslated region; WT, wild type 3'-untranslated region.

expression levels of miR-216b-3p in all lung adenocarcinoma cell lines (A549, GLC-82 and H358 cells) were significantly lower compared with BEAS-2B cells. The lowest expression level of miR-216b-3p was in GLC-82 cells (Fig. 1). Therefore, GLC-82 cells were selected for subsequent in vitro studies in the present study.

Overexpression of $P B K / T O P K$ in lung adenocarcinoma cell lines. Western blotting and RT-qPCR were performed to test whether PBK/TOPK was overexpressed in lung adenocarcinoma cell lines. PBK/TOPK was expressed at low levels within BEAS-2B cells. However, the protein and mRNA expression levels of PBK/TOPK were increased in all lung adenocarcinoma cell lines (A549, GLC-82 and H358 cells), compared with BEAS-2B cells, with the largest increase in GLC-82 (Fig. 2). These results suggested that PBK/TOPK may be a target of activation in lung adenocarcinoma.

$P B K$ is a direct target gene of $m i R-216 b-3 p$. The aforementioned results demonstrated that miR-216b-3p and PBK/TOPK expression may be dysregulated in lung adenocarcinoma cell lines. Therefore, miR-216b-3p and PBK/TOPK may have a direct association. TargetScan was employed to predict the target gene of miR-216b-3p (Fig. 3A). PBK was identified as a direct target gene of miR-216b-3p and a double luciferase reporter assay revealed the same result (Fig. 3B).

To investigate the function of miR-216b-3p in lung adenocarcinoma, synthesized miR-216b-3p mimics, miR-NC,

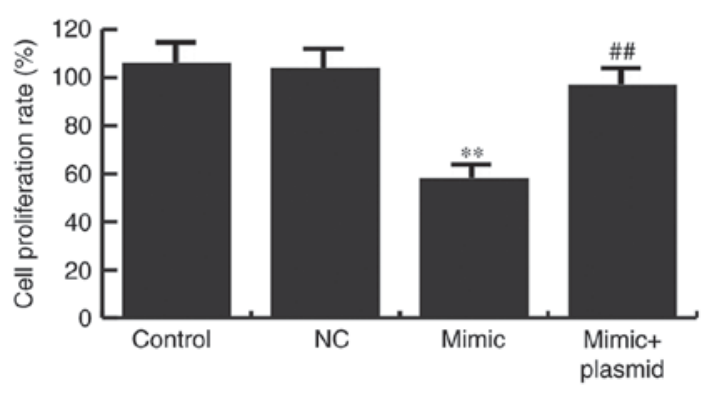

Figure 4. Effects of miR-216b-3p on GLC-82 cell proliferation. At $48 \mathrm{~h}$ post-transfection, an MTT assay was used to determine the effect of miR-216b-3p on GLC-82 cell proliferation. Data are presented as the mean \pm standard deviation. ${ }^{* *} \mathrm{P}<0.01$ vs. control; ${ }^{\#} \mathrm{P}<0.01$ vs. mimic. Control, control group, cells without any treatment; $\mathrm{NC}$, negative control group, cells transfected with the negative control vector of miR-216b-3p mimics; mimic, cells transfected with miR-216b-3p mimics; mimic + plasmid, cells co-transfected with miR-216b-3p mimics and PDZ-binding-kinase/T-LAK cell-originated protein kinase plasmids; miR, microRNA.

control plasmids, PBK/TOPK plasmids or miR-216b-3p mimic + PBK/TOPK plasmids were transfected into GLC-82 cells (Fig. 3C-F). At 48 h post-transfection, the transfection efficiency was determined by RT-qPCR (Fig. 3C and F). The results indicated that miR-216b-3p mimics significantly enhanced miR-216-3p expression in GLC-82 cells and PBK/TOPK plasmids significantly increased the mRNA level of PBK/TOPK. To further reveal whether miR-216b-3p may regulate PBK/TOPK in GLC-82 cells, at $48 \mathrm{~h}$ after GLC-82 
A

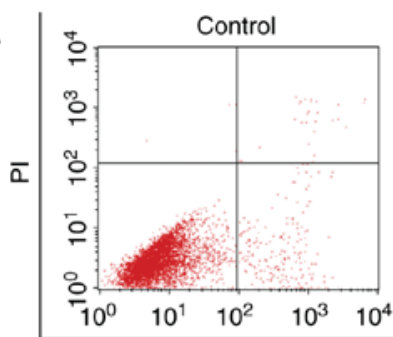

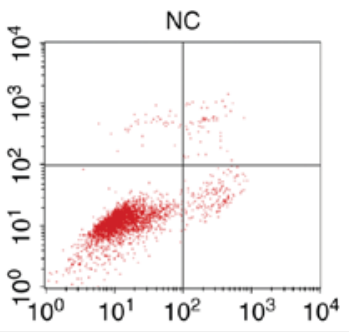
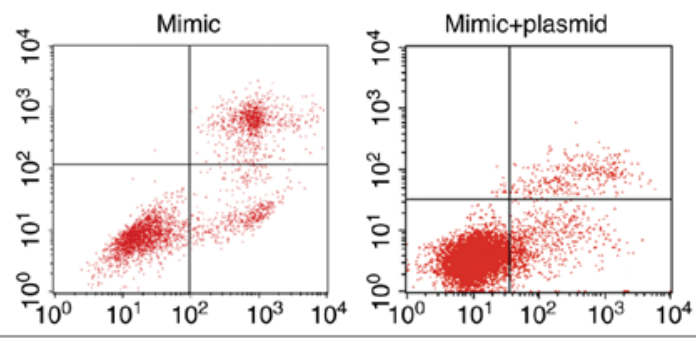

FITC

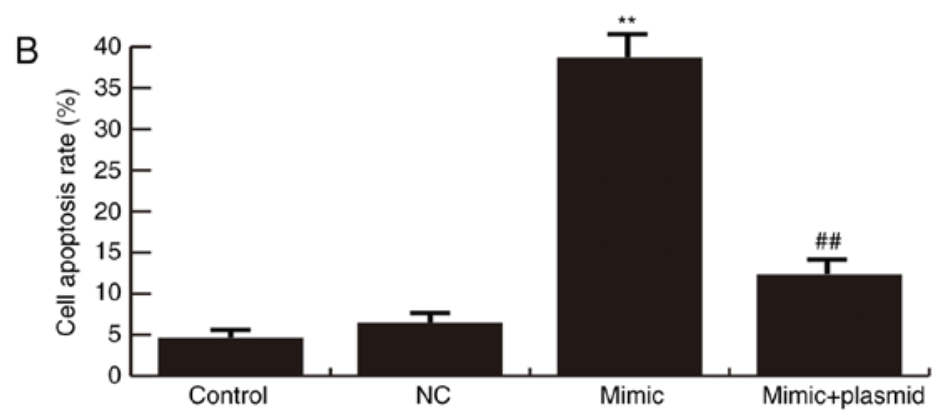

Figure 5. Effects of miR-216b-3p on GLC-82 cell apoptosis. (A) At $48 \mathrm{~h}$ post-transfection, flow cytometry was performed to determine the effect of miR-216b-3p on GLC-82 cell apoptosis. Cell apoptosis=early apoptosis (lower right quadrant) + late apoptosis (upper right quadrant). (B) Data are presented as the mean \pm standard deviation. ${ }^{* *} \mathrm{P}<0.01 \mathrm{vs}$. control; ${ }^{\# \#} \mathrm{P}<0.01 \mathrm{vs}$. mimic. Control, control group, cells without any treatment; $\mathrm{NC}$, negative control group, cells transfected with the negative control vector of miR-216b-3p mimics; mimic, cells transfected with miR-216b-3p mimics; mimic + plasmid, cells co-transfected with miR-216b-3p mimics and PDZ-binding-kinase/T-LAK cell-originated protein kinase plasmids; miR, microRNA.

cell transfection with miR-216b-3p mimics or miR-NC, the protein and mRNA expression levels of PBK/TOPK were detected by western blotting and RT-qPCR respectively. The results of the present study indicated that miR-216b-3p mimics may inhibit PBK/TOPK expression in GLC-82 cells (Fig. 3D and E). Collectively, the data suggested that PBK may be a direct target gene of miR-216b-3p and may be negatively regulated by miR-216b-3p.

miR-216b-3p overexpression inhibits GLC-82 cell proliferation and induces cell apoptosis via regulating PBK/TOPK expression. Cells were transiently transfected with miR-216b-3p mimics, miR-NC or miR-216b-3p mimics + PBK/TOPK plasmids. An MTT assay was conducted to detect the proliferation of GLC-82 cells; flow cytometry was used to analyze apoptosis. The results demonstrated that miR-216b-3p overexpression significantly inhibits GLC-82 cell proliferation (Fig. 4) and induces cell apoptosis (Fig. 5) compared with the control. These effects were eliminated by PBK/TOPK overexpression (Figs. 4 and 5).

miR-216b-3p overexpression affects p53, p21 and phosphorylated $(p)-p 38$ expression. To further investigate the molecular mechanism of miR-216b-3p, the expression of p53, p21 and p-p38 was detected by western blot analysis. The results demonstrated that the overexpression of miR-216b-3p increased the expression of p53 and p21, and decreased the expression of $\mathrm{p}-\mathrm{p} 38$. These effects also appeared to be eliminated by PBK/TOPK overexpression (Fig. 6).

\section{Discussion}

According a previous report, miRNAs serve a regulatory role in cell growth, proliferation, apoptosis, differentiation,

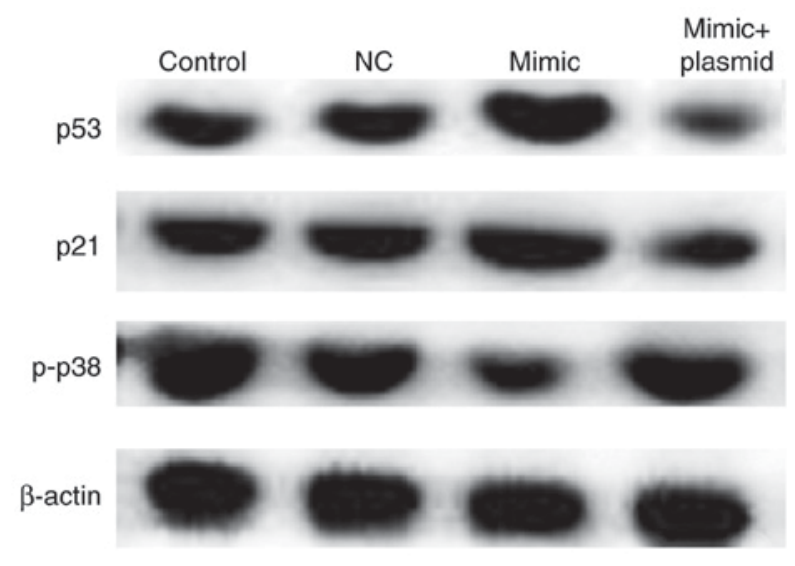

Figure 6. Effects of miR-216b-3p on the expression of p53, p21 and p-p38 in GLC-82 cells. After $48 \mathrm{~h}$ post-transfection, western blotting was performed to determine the effect of miR-216b-3p the expression of p53, p21 and p-p38 in GLC-82 cells. Control, control group, cells without any treatment; NC, negative control group, cells transfected with the negative control vector of miR-216b-3p mimics; mimic, cells transfected with miR-216b-3p mimics; mimic + plasmid, cells co-transfected with miR-216b-3p mimics and PDZ-binding-kinase/T-LAK cell-originated protein kinase plasmids. miR, microRNA; p-, phosphorylated.

migration and metabolism (34). In the present study, the expression of miR-216b-3p was detected in a variety of lung adenocarcinoma cell lines and the results demonstrated that within all lung adenocarcinoma cell lines (A549, GLC-82 and $\mathrm{H} 358$ cells), miR-216b-3p expression levels was significantly lower compared with BEAS-2B cells. This indicated that miR-216b-3p was associated with lung adenocarcinoma. GLC-82 cells, which expressed the lowest level of miR-216b-3b, were selected for further analysis.

$\mathrm{PBK} / \mathrm{TOPK}$ gene expression is increased in various types of cancer, including bladder cancer, brain tumors, breast 
cancer, liver cancer, lung cancer and sarcoma $(35,36)$. In the present study, the expression levels of PBK/TOPK were observed to be significantly increased within lung adenocarcinoma cells. These results suggested that the expression of miR-216b-3p and PBK/TOPK was dysregulated in lung cancer. Therefore, miR-216b-3p may be involved in tumor development by regulating PBK/TOPK expression. TargetScan was used to predict the target gene of miR-216b-3p, which suggested that miR-216b-3p was targeted to PBK and a double luciferase reporter gene system validated this result. Furthermore, the overexpression of miR-216b-3p in GLC-82 cells significantly inhibited cell proliferation and induced cell apoptosis; when co-transfected with PBK/TOPK, the inhibitory effect exerted by $\mathrm{miR}-216 \mathrm{~b}-3 \mathrm{p}$ was reversed. These results indicated that miR-216b-3p may be considered to be a tumor suppressor by decreasing the expression of $\mathrm{PBK} / \mathrm{TOPK}$.

As a member of the mitogen-activated protein kinase kinase family, PBK/TOPK protein is highly expressed in various types of cancer. p53 is considered to be one of the most common tumor suppressors; wild type p53 is involved in apoptosis, cell-cycle arrest and DNA repair (37). The loss of p53 function caused by mutations, however, is associated with the majority of human cancers (38). Mutant p53 is able to not only promote invasion, migration and proliferation, but also enhance genomic instability and chemoresistance (39). It was reported that a p53 mutation is closely associated with the occurrence and progression of lung cancer (40). Additionally, Hu et al (7) revealed that PBK/TOPK may inhibit p53 function and promote the development and progression of tumor cells. The expression levels of p53, p21 and p-p38 were also determined in the present study, and the data demonstrated that the overexpression of miR-216b-3p may inhibit PBK/TOPK. Thus, increases in p53 and $\mathrm{p} 21$, and decreases in $\mathrm{p}-\mathrm{p} 38$ expression, may exert an antitumor effect.

In summary, the present study provided novel evidence that decreased $\mathrm{miR}-216 \mathrm{~b}-3 \mathrm{p}$ expression may contribute to lung adenocarcinoma development by increasing the expression of PBK/TOPK. Furthermore, PBK/TOPK expression may be beneficial to the promotion of cell proliferation and viability. Therefore, miR-216b-3p and PBK/TOPK may be considered as potential clinical indicators and therapeutic targets for the treatment of lung adenocarcinoma.

\section{Acknowledgements}

The authors would like to thank Dr Shuo Wu, Deputy Chief Physician, Department of Respiratory Medicine, XiJing Hospital, for assistance with the experiments.

\section{References}

1. de Groot P and Munden RF: Lung cancer epidemiology, risk factors, and prevention. Radiol Clin North Am 50: 863-876, 2012.

2. KrawczykP,Nicoś M, Ramlau R, Powrózek T, Wojas-Krawczyk K, Sura S, Jarosz B, Szumiło J, Warda E, Mazurkiewicz T, et al: The incidence of EGFR-activating mutations in bone metastases of lung adenocarcinoma. Pathol Oncol Res 20: 107-112, 2014.

3. Jiang X, de Groh M, Liu S, Liang H and Morrison H: Rising incidence of adenocarcinoma of the lung in Canada. Lung Cancer 78: 16-22, 2012.
4. Travis WD, Brambilla E, Noguchi M, Nicholson AG, Geisinger K Yatabe Y, Powell CA, Beer D, Riely G, Garg K, et al: International Association for the Study of Lung Cancer/American Thoracic Society/European Respiratory Society: International multidisciplinary classification of lung adenocarcinoma: Executive summary. Proc Am Thorac Soc 8: 381-385, 2011.

5. Siegel RL, Miller KD and Jemal A: Cancer statistics, 2015. CA Cancer J Clin 65: 5-29, 2015.

6. Lei B, Qi W, Zhao Y, Li Y, Liu S, Xu X, Zhi C, Wan L and Shen H: PBK/TOPK expression correlates with mutant p53 and affects patients' prognosis and cell proliferation and viability in lung adenocarcinoma. Hum Pathol 46: 217-224, 2015.

7. $\mathrm{Hu}$ F, Gartenhaus RB, Eichberg D, Liu Z, Fang HB and Rapoport AP: PBK/TOPK interacts with the DBD domain of tumor suppressor p53 and modulates expression of transcriptional targets including p21. Oncogene 29: 5464-5474, 2010.

8. Park JH, Lin ML, Nishidate T, Nakamura Y and Katagiri T: PDZ-binding kinase/T-LAK cell-originated protein kinase, a putative cancer/testis antigen with an oncogenic activity in breast cancer. Cancer Res 66: 9186-9195, 2006.

9. Gaudet S, Branton D and Lue RA: Characterization of PDZ-binding kinase, a mitotic kinase. Proc Natl Acad Sci USA 97: 5167-5172, 2000.

10. Simons-Evelyn M, Bailey-Dell K, Toretsky JA, Ross DD, Fenton R, Kalvakolanu D and Rapoport AP: PBK/TOPK is a novel mitotic kinase which is upregulated in Burkitt's lymphoma and other highly proliferative malignant cells. Blood Cells Mol Dis 27: 825-829, 2001.

11. Ayllón V and O'connor R: PBK/TOPK promotes tumour cell proliferation through p38 MAPK activity and regulation of the DNA damage response. Oncogene 26: 3451-3461, 2007.

12. Stricker TP, Henriksen KJ, Tonsgard JH, Montag AG, Krausz TN and Pytel P: Expression profiling of 519 kinase genes in matched malignant peripheral nerve sheath tumor/plexiform neurofibroma samples is discriminatory and identifies mitotic regulators BUB1B, PBK and NEK2 as overexpressed with transformation. Mod Pathol 26: 930-943, 2013.

13. Kim DJ, Li Y, Reddy K, Lee MH, Kim MO, Cho YY, Lee SY, Kim JE, Bode AM and Dong Z: Novel TOPK inhibitor HI-TOPK-032 effectively suppresses colon cancer growth. Cancer Res 72: 3060-3068, 2012.

14. Herrero-Martín D, Osuna D, Ordóñez JL, Sevillano V, Martins AS, Mackintosh C, Campos M, Madoz-Gúrpide J, Otero-Motta AP, Caballero G, et al: Stable interference of EWS-FLI1 in an Ewing sarcoma cell line impairs IGF-1/IGF-1R signaling and reveals TOPK as a new target. Br J Cancer 101: 80-90, 2009.

15. Lei B, Liu S, Qi W, Zhao Y, Li Y, Lin N, Xu X, Zhi C, Mei J, Yan Z, et al: PBK/TOPK expression in non-small-cell lung cancer: Its correlation and prognostic significance with Ki67 and p53 expression. Histopathology 63: 696-703, 2013.

16. Ohashi T, Komatsu S, Ichikawa D, Miyamae M, Okajima W, Imamura T, Kiuchi J, Kosuga T, Konishi H, Shiozaki A, et al: Overexpression of PBK/TOPK relates to tumour malignant potential and poor outcome of gastric carcinoma. Br J Cancer 116: 218-226, 2017.

17. Chang CF, Chen SL, Sung WW, Hsieh MJ, Hsu HT, Chen LH, Chen MK, Ko JL, Chen CJ and Chou MC: PBK/TOPK expression predicts prognosis in oral cancer. Int J Mol Sci 17, 2016.

18. Hu F, Gartenhaus RB, Zhao XF, Fang HB, Minkove S, Poss DE and Rapoport AP: c-Myc and E2F1 drive PBK/TOPK expression in high-grade malignant lymphomas. Leuk Res 37: 447-454, 2013.

19. Bartel DP: MicroRNAs: Genomics, biogenesis, mechanism and function. Cell 116: 281-297, 2004.

20. Calin GA and Croce CM: MicroRNA signatures in human cancers. Nat Rev Cancer 6: 857-866, 2006.

21. Inui M, Martello G and Piccolo S: MicroRNA control of signal transduction. Nat Rev Mol Cell Biol 11: 252-263, 2010.

22. Png KJ, Halberg N, Yoshida M and Tavazoie SF: A microRNA regulon that mediates endothelial recruitment and metastasis by cancer cells. Nature 481: 190-194, 2011.

23. Croce CM: Causes and consequences of microRNA dysregulation in cancer. Nat Rev Genet 10: 704-714, 2009.

24. Ameres SL and Zamore PD: Diversifying microRNA sequence and function. Nat Rev Mol Cell Biol 14: 475-488, 2013.

25. He S, Liao B, Deng Y, Su C, Tuo J, Liu J, Yao S and Xu L: miR-216b inhibits cell proliferation by targeting FOXM1 in cervical cancer cells and is associated with better prognosis. BMC Cancer 17: 673, 2017. 
26. Zhang T, Ma G, Zhang Y, Huo H and Zhao Y: miR-216b inhibits glioma cell migration and invasion through suppression of FoxM1. Oncol Rep 38: 1751-1759, 2017.

27. Liu Y, Niu Z, Lin X and Tian Y: miR-216b increases cisplatin sensitivity in ovarian cancer cells by targeting PARP1. Cancer Gene Ther 24: 208-214, 2017.

28. Liu FY, Zhou SJ, Deng YL, Zhang ZY, Zhang EL, Wu ZB Huang ZY and Chen XP: miR-216b is involved in pathogenesis and progression of hepatocellular carcinoma through HBx-miR-216b-IGF2BP2 signaling pathway. Cell Death Dis 6 : e1670, 2015.

29. Livak KJ and Schmittgen TD: Analysis of relative gene expression data using real-time quantitative PCR and the 2(-Delta Delta C(T)) method. Methods 25: 402-408, 2001

30. Meng SF, Mao WP, Wang F, Liu XQ and Shao LL: The relationship between $\mathrm{Cd}$-induced autophagy and lysosomal activation in WRL-68 cells. J Appl Toxicol 35: 1398-1405, 2015.

31. Feng YL, Yin YX, Ding J, Yuan H, Yang L, Xu JJ and Hu LQ: Alpha-1-antitrypsin suppresses oxidative stress in preeclampsia by inhibiting the p38MAPK signaling pathway: An in vivo and in vitro study. PLoS One 12: e0173711, 2017.

32. Zou J, Kuang W, Hu J and Rao H: miR-216b promotes cell growth and enhances chemosensitivity of colorectal cancer by suppressing PDZ-binding kinase. Biochem Biophys Res Commun 488: 247-252, 2017.

33. Gao S, Li X, Ding X, Qi W and Yang Q: Cepharanthine Induces autophagy, apoptosis and cell cycle arrest in breast cancer cells. Cell Physiol Biochem 41: 1633-1648, 2017.
34. Rottiers V,Najafi-Shoushtari SH,Kristo F, Gurumurthy S, Zhong L, Li Y, Cohen DE, Gerszten RE, Bardeesy N, Mostoslavsky R and Näär AM: MicroRNAs in metabolism and metabolic diseases. Cold Spring Harb Symp Quant Biol 76: 225-233, 2011.

35. Singh PK, Srivastava AK, Dalela D, Rath SK, Goel MM and Bhatt ML: Expression of PDZ-binding kinase/T-LAK celloriginated protein kinase (PBK/TOPK) in human urinary bladder transitional cell carcinoma. Immunobiology 219: 469-474, 2014.

36. Joel M, Mughal AA, Grieg Z, Murrell W, Palmero S, Mikkelsen B, Fjerdingstad HB, Sandberg CJ, Behnan J, Glover JC, et al: Targeting PBK/TOPK decreases growth and survival of glioma initiating cells in vitro and attenuates tumor growth in vivo. Mol Cancer 14: 121, 2015.

37. Riley T, Sontag E, Chen P and Levine A: Transcriptional control of human p53-regulated genes. Nat Rev Mol Cell Biol 9: 402-412, 2008.

38. Liu X, Wilcken R, Joerger AC, Chuckowree IS, Amin J, Spencer J and Fersht AR: Small molecule induced reactivation of mutant p53 in cancer cells. Nucleic Acids Res 41: 6034-6044, 2013.

39. Muller PA and Vousden KH: p53 mutations in cancer. Nat Cell Biol 15: 2-8, 2013.

40. Jackson JG and Lozano G: The mutant p53 mouse as a pre-clinical model. Oncogene 32: 4325-4330, 2013.

This work is licensed under a Creative Commons Attribution-NonCommercial-NoDerivatives 4.0 International (CC BY-NC-ND 4.0) License. 